\title{
REDUCTION OF CEMENT CONSUMPTION BY THE AID OF SILICA NANO-PARTICLES (INVESTIGATION ON CONCRETE PROPERTIES)
}

\author{
Hadi Bahadori ${ }^{1}$, Payam Hosseini ${ }^{2}$ \\ ${ }^{1}$ College of Engineering, Urmia University, 15311-57561 Urmia, Iran \\ ${ }^{2}$ Department of Civil Engineering, Sharif University of Technology, Tehran, Iran \\ E-mails: ${ }^{1}$ h.bahadori@urmia.ac.ir (corresponding author); ${ }^{2}$ p.hosseini87@gmail.com \\ Received 10 Aug. 2010; accepted 14 Mar. 2011
}

\begin{abstract}
In this study, effects of replacing cement with colloidal amorphous silica nano-particles have been experimentally investigated on the physical and mechanical properties, durability and microstructure of concrete. Experimental results include workability, fresh concrete density, and hardened concrete properties like compressive strength at different ages of 3, 7, and 28-days, and also 28-days splitting tensile strength. Furthermore, influence of silica nano-particles on durability and microstructure of concrete for 28-days specimens was tested by conducting water absorption test, Scanning Electron Microscopy (SEM), and Energy Dispersive X-ray Analysis (EDAX), respectively. In order to study the effect of replacement of cement with silica nano-particles, specimens with $10 \%, 20 \%$, and $30 \%$ cement reduction, and addition of $1 \%, 2 \%$, and $3 \%$ silica nano-particles with respect to witness specimen were fabricated. Experimental results revealed that $20 \%$ reduction of cement combining $2 \%$ silica nano-particles and also $10 \%$ cement reduction combined with $1 \%$ silica nano-particles enhance the microstructure of concrete, despite unnoticeable compressive and tensile strength loss. By remarkable reduction of cement consumption and addition of silica nano-particles, strength almost remains constant and consequently decreasing the cement content will become possible. Also, in all specimens, increase in nano-particles content and decrease in cement usage contributed to workability loss. Therefore, applying super-plasticizers seems indispensible while using silica nano-particles. On the other side, according to water absorption test, concretes containing nanoparticles showed more appropriate durability.
\end{abstract}

Keywords: nano- $\mathrm{SiO}_{2}$ particles, cement substitution, workability, compressive strength, splitting tensile strength, water absorption, microstructure.

\section{Introduction}

Due to development of concrete constructions throughout the world, it can be seen that the cement usage has been increased. Regarding the increase in cement demand, measures should be taken in order to decide among either producing more amounts of cement or replacing it with other materials. Because of the numerous harms caused by cement production especially for environment, it is mandatory to find solutions by replacing the cement with proper materials. The importance of this issue is in such a way that the topic of cement reduction is propounded as one of the principal keys in achieving a sustainable development in concrete industry (Damtoft et al. 2008; Ortiz et al. 2009; Bahadori et al. 2009; Khaloo, Hosseini 2009). Based on these researches, various types of pozzolans such as class $F$ fly ash, slag, silica fume, rice husk ash were recognized and utilized to enhance the concrete quality (Hale et al. 2008; Penpolcharoen 2005; Roy et al. 2001; Li, Zhao 2003; Chung 2002; Ramezanianpour et al. 2009).

However it is not a long time passed from the entrance of nano-technology in concrete industry, many researches and investigations claimed the positive effects of nano-materials and nano-powders on microstructure and macrostructure of concrete (Li et al. 2004b; Jo et al. 2007;
Qing et al. 2007; Hosseini et al. 2010a, b; Senff et al. $2009,2010)$. In many fields, application of nano-materials initiated the designation and production of modern materials with advanced performances (Senff et al. 2009; Naji Givi et al. 2010). When ultra-fine particles are added in cement-based materials, different performances will be achieved as compared with conventional materials. These singular behaviors can be caused by physical and chemical properties of nano-particles. As an example, by increasing the specific surface area of particles (especially in nanoscale), the effecting power of nano-particles in enhancing the pozzolanic reaction can be intensified.

Performance of cement-based materials is intensely dependent on nano-scale solid particles such as CalciumSilicate-Hydrate (C-S-H) and Nano-sized porosity existing in interfacial transition zone between cement and aggregate particles (Senff et al. 2009). From those features dependent on nano-particles and nano-sized porosity, strength, durability, shrinkage, and steel-bond can be mentioned (Collepardi et al. 2005; Zhang, Li 2011). Therefore, regarding the existence of plenty of voids with different micro to nano-meter scales in interfacial transition zone, there exists much room for improvement of cement composites by incorporating nano-materials into the cement based materials matrix (Li et al. 2006a). 
On the other hand, singular behavior of silica nanoparticles in concrete matrix has introduced this material as a super-pozzolan (Li et al. 2004b; Qing et al. 2007; Hosseini et al. 2010a; Ji 2005) based on concentrated volume of $\mathrm{SiO}_{2}$ which is known as the most fundamental factor in pozzolanic reaction (Khaloo, Hosseini 2008). Hence, according to discussed issues, the target of this study is to examine the feasibility of strategy of using nano-particles to reduce cement consumption in mix proportions of high strength concretes.

Thus, for each cement reduction percentage $(10,20$, and $30 \%)$ three different nano-particle contents (1, 2 and $3 \%$ ) were tested and compared with the witness specimen. Experimental results include workability, fresh concrete density, and hardened concrete properties like compressive strength at different ages of 3,7 and 28-days, and also 28-days splitting tensile strength. Furthermore, influence of silica nano-particles on durability and microstructure of concrete for 28-days specimens were tested by conducting water absorption test, Scanning Electron Microscopy (SEM), and Energy Dispersive $\mathrm{X}$-ray Analysis (EDAX), respectively. According to results of this study, the possibility of replacing some parts of cement with silica nano-particles was confirmed under specific situation; and authors of this study are still trying to develop and improve the resulted features.

\section{Materials and mix proportioning}

Cementitious materials in this study are Portland cement and silica nano-particles. Ordinary available Portland cement (type I-425) is produced in Tehran Cement Factory in Iran which complies with Iranian code No. 389. Silica nano-particles are purchased from India. Chemical and physical properties of cement and silica nano-particles are pointed in Tables 1 and 2, respectively. Colloidal nanosilica possesses $30 \%$ dry content. The super-plasticizer is naphthalene type with $33 \%$ solid content and $1.15 \mathrm{gr} / \mathrm{cm}^{3}$ density. Because of ultra high specific surface area of nano-particles, these particles absorb some part of water content and reduce the workability of fresh concrete.

Consequently, super-plasticizer is used for better workability, and water reducing agent was added to make equal dispersion and distribution of nano-particles in

Table 1. Chemical and physical composition of Portland cement (type I-425)

\begin{tabular}{c|c}
\hline \multicolumn{2}{c}{ Chemical properties } \\
\hline Components & By mass (\%) \\
\hline $\mathrm{CaO}$ & 64 \\
\hline $\mathrm{SiO}_{2}$ & 21.4 \\
\hline $\mathrm{Al}_{2} \mathrm{O}_{3}$ & 6 \\
\hline $\mathrm{Fe}_{2} \mathrm{O}_{3}$ & 3.4 \\
\hline $\mathrm{MgO}^{\mathrm{SgO}}$ & 1.8 \\
\hline $\mathrm{SO}_{3} \mathrm{O}+\mathrm{Na}_{2} \mathrm{O}$ & 1.4 \\
\hline $\mathrm{L} . \mathrm{O} . \mathrm{I}$ & 1 \\
\hline \multicolumn{2}{c}{ Physical properties } \\
\hline Blaine $\left(\mathrm{m}^{2} / \mathrm{kg}\right)$ & 3 \\
\hline Specific gravity $\left(\mathrm{kg} / \mathrm{m}^{3}\right)$ & 311 \\
\hline
\end{tabular}

Table 2. Chemical and physical properties of silica nano-particles

\begin{tabular}{c|c}
\hline $\mathrm{SiO}_{2}$ content $(\%)$ & $>98.9$ \\
\hline Average particle size $(\mathrm{nm})$ & 10 \\
\hline $\mathrm{PH}$ & 10 \\
\hline Specific surface area $\left(\mathrm{m}^{2} / \mathrm{kg}\right)$ & 250000 \\
\hline Apparent density $\left(\mathrm{kg} / \mathrm{m}^{3}\right)$ & 200 \\
\hline
\end{tabular}

concrete mixture due to extreme intention of silica nanoparticles toward agglomeration and conglomeration based on their high specific surface area (Hosseini et al. 2010a, b). According to Fig. 1, by applying X-Ray Diffraction test (XRD), it was revealed that silica nano-particles were in amorphous phase. Amorphous silica possesses appropriate specific surface regarding its dissimilar structure, and is used as concrete admixture. Inexistence of any special peak in XRD results proves the amorphous structure of this powder.

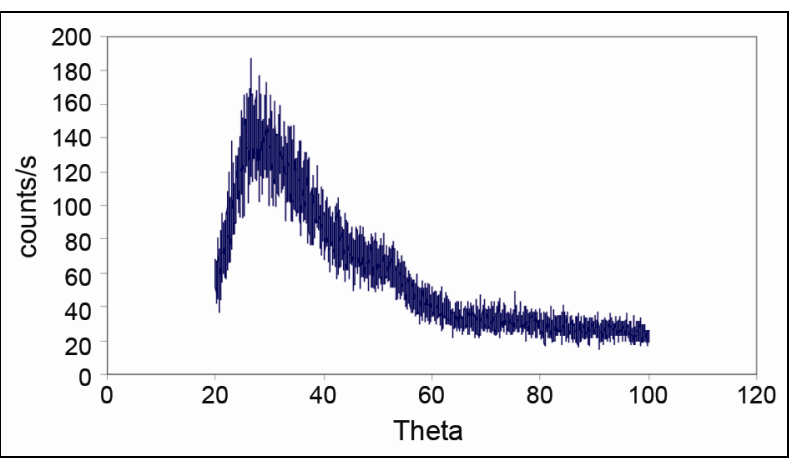

Fig. 1. XRD results for silica nano-particles

Washed natural aggregate with Nominal maximum aggregate size (NMAS) of $4.74 \mathrm{~mm}$ and crushed limestone with NMAS of $19 \mathrm{~mm}$ were used as fine and coarse aggregate, respectively. Fineness modulus of fine aggregates is 3.1 and saturated surface dry density of fine aggregates is $2.64 \mathrm{gr} / \mathrm{cm}^{3}$ according to ASTM C128-01 (2001), and saturated surface dry density of coarse aggregates is $2.68 \mathrm{gr} / \mathrm{cm}^{3}$ according to ASTM C127-01 (2001).

Witness mixture is fabricated with $500 \mathrm{~kg} / \mathrm{m}^{3}$ cement content, while different percentages of silica nanoparticles were replaced with cement in other mixtures. The witness specimen is labeled with ' $\mathrm{C}$ '. In each series, $1,2,3 \%$ of weight of initial cement content of witness mixture were replaced by silica nano-particles.

It is worthy of mention that different ratios of cement replacement with silica nano-particles were selected, because the target of this study is to reduce the cement content by using silica nano-particles; hence, the best replacement ratio which contributes to similar properties should be investigated. Water to binder ratio was held constant and equal to 0.33 for all mixtures in order to omit the effect of these variations in final results. The ratio of water reducer super-plasticizer respect to weight of cement content for all mixtures was equal to $1 \%$ to prohibit the influences of different dosages of superplasticizer on workability of fresh mixtures. Optimum ratio of coarse to fine aggregate was calculated equal to 
'11/9' by experimental tests to provide a continuous aggregate grading helping us in achieving high strength concrete. Mix proportions are shown in Table 3. Also Table 4 described short descriptions about mixtures.

Table 3. Mix proportions $\left(\mathrm{kg} / \mathrm{m}^{3}\right.$ of concrete)

\begin{tabular}{c|c|c|c|c|c|c}
\hline $\begin{array}{c}\text { Mix. } \\
\text { No }\end{array}$ & Water & Cement & $\mathrm{G}^{*}$ & $\mathrm{~S}^{* *}$ & $\mathrm{SP}^{\star}$ & $\mathrm{S}^{\star \star *}$ \\
\hline C & 165 & 500 & 982 & 806 & 5.00 & 0 \\
\hline D1 & 150.15 & 450 & 1007 & 827 & 4.55 & 5 \\
\hline D2 & 151.8 & 450 & 985 & 808 & 4.60 & 10 \\
\hline D3 & 153.45 & 450 & 962 & 790 & 4.65 & 15 \\
\hline E1 & 133.65 & 400 & 1055 & 866 & 4.05 & 5 \\
\hline E2 & 135.3 & 400 & 1033 & 848 & 4.10 & 10 \\
\hline E3 & 136.95 & 400 & 1010 & 829 & 4.15 & 15 \\
\hline F1 & 117.15 & 350 & 1103 & 906 & 3.55 & 5 \\
\hline F2 & 118.8 & 350 & 1081 & 887 & 3.60 & 10 \\
\hline F3 & 120.45 & 350 & 1058 & 868 & 3.65 & 15 \\
\hline
\end{tabular}

*G: Gravel; ${ }^{*}$ S: Sand; ^SP: Superplasticizer;

${ }^{\star A} \mathrm{~S}$ : Silica nano-particles in dry state

Table 4. Mixtures descriptions

\begin{tabular}{c|c|c}
\hline Mix. No & $\begin{array}{c}\text { Water to binder } \\
\text { ratio (W/B) }\end{array}$ & Description \\
\hline C & 0.33 & Basic mixture \\
\hline D1 & 0.33 & $\begin{array}{c}10 \% \text { cement reduction and } \\
1 \% \text { nano-silica addition }\end{array}$ \\
\hline D2 & 0.33 & $\begin{array}{c}10 \% \text { cement reduction and } \\
2 \% \text { nano-silica addition }\end{array}$ \\
\hline D3 & 0.33 & $\begin{array}{c}10 \% \text { cement reduction and } \\
3 \% \text { nano-silica addition }\end{array}$ \\
\hline E1 & 0.33 & $\begin{array}{c}20 \% \text { cement reduction and } \\
1 \% \text { nano-silica addition }\end{array}$ \\
\hline E2 & 0.33 & $\begin{array}{c}20 \% \text { cement reduction and } \\
2 \% \text { nano-silica addition }\end{array}$ \\
\hline E3 & 0.33 & $\begin{array}{c}20 \% \text { cement reduction and } \\
3 \% \text { nano-silica addition }\end{array}$ \\
\hline F1 & 0.33 & $\begin{array}{c}30 \% \text { cement reduction and } \\
1 \% \text { nano-silica addition }\end{array}$ \\
\hline F2 & 0.33 & $\begin{array}{c}30 \% \text { cement reduction and } \\
2 \% \text { nano-silica addition }\end{array}$ \\
\hline F3 & 0.33 & $\begin{array}{c}3 \% \% \text { cement reduction and } \\
3 \% \text { nano-silica addition }\end{array}$ \\
\hline
\end{tabular}

For each mix proportion, $100 \mathrm{~mm}$ cubes for compressive strength test, $150 \mathrm{~mm}$ cubes for water absorption test, and $100 \times 200 \mathrm{~mm}$ cylinders for splitting tensile strength test were fabricated. In order to cast concretes containing nano-particles, water reducer super-plasticizer and water were mixed in mixer, and then silica nanoparticles were added, and mixed with high speed for 5 minutes. Cement, fine, and coarse aggregates were also added for 2 more minutes in rotary mixer with low speed to procure a fresh mixture with suitable workability.

Finally, fresh concrete were poured in same moulds. In the next step, an exterior vibrator was used to ease the compaction process of concrete and reduce existing air voids in the matrix of fresh concrete. Specimens were taken out of moulds after 24 hours and cured in the curing room ( $95 \%$ humidity and temperature of $20 \pm 3{ }^{\circ} \mathrm{C}$ ) for 3 , 7 and 28 days of curing.

From each mixture, two moulds for compressive strength, two moulds for 28-days water absorption test, and two other moulds for splitting tensile strength were sampled and experimental data were considered as average of each two specimens. To apply the compressive and tensile strength test 200 ton materials testing machine was utilized. Compressive strength tests were done at 3, 7 and 28 days. Water absorption test, Brazilian tensile strength test, SEM, and EDAX, were applied on 28-days specimens. Compressive strength test was conducted according to BS 1881-113:2011 (2011) part117 on $100 \mathrm{~mm}$ cubes. Tensile strength test on $100 \times 200 \mathrm{~mm}$ cylinder was applied according to ASTM C496/C496M-11 (2011). In this test, compressive load is applied on $150 \times 300 \mathrm{~mm}$ cylinder (according to ASTM C496/C496M-11) while here smaller cylinders were utilized. Therefore, higher values are achieved comparing conventional tests.

Water can penetrate in the form of liquid or vapor within capillary voids into the porous material. Absorption is the trend in which concrete attracts water toward pores and capillary voids. The water absorption value is a representative for durability of concrete. According to ASTM C642-97 (1997), cylindrical samples with $50 \mathrm{~mm}$ diameter and $100 \mathrm{~mm}$ height were taken out from $150 \mathrm{~mm}$ cubes and water absorption test was applied.

In addition, slump test and fresh concrete unit weight were performed complying with ASTM C143-03 (2003) and ASTM C138-01 (2001), respectively. Finally, after applying the mechanical tests at 28 days, the crushed specimens were selected for SEM and EDAX tests to observe the effect of nano-particles on properties of Interfacial Transition Zone (ITZ) between cement paste and aggregates.

\section{Results and discussions}

Results for slump test, unit weight of fresh concrete, Splitting tensile strength, and water absorption tests are shown in Table 5. In the following, analysis and interpretation of results are discussed.

Table 5. Results of different tests

\begin{tabular}{|c|c|c|c|c|c|c|c|}
\hline \multirow{3}{*}{$\begin{array}{c}\text { Mix. } \\
\text { No }\end{array}$} & $\begin{array}{r}\mathrm{C} \\
\text { Stre }\end{array}$ & $\begin{array}{l}\text { pres } \\
\text { th }(\end{array}$ & $\begin{array}{l}\text { e } \\
\text { a) }\end{array}$ & $\begin{array}{l}\text { STS }^{*} \\
(\mathrm{MPa})\end{array}$ & $\begin{array}{l}\mathrm{WA}^{*} \\
(\%)\end{array}$ & \multirow{3}{*}{$\begin{array}{c}\mathrm{S}^{* 0} \\
(\mathrm{~mm})\end{array}$} & \multirow{3}{*}{$\mathrm{FD}^{\star 4}$} \\
\hline & \multicolumn{5}{|c|}{ Curing days } & & \\
\hline & 3 & 7 & 28 & 28 & 28 & & \\
\hline $\mathrm{C}$ & 19.8 & 43.9 & 70.1 & 6.8 & 1.62 & $90-100$ & 2.47 \\
\hline D1 & 19.2 & 37.9 & 68.6 & 6.5 & 1.51 & $60-70$ & 2.46 \\
\hline D2 & 15.7 & 31.2 & 62.1 & 5.8 & 1.40 & $30-40$ & 2.44 \\
\hline D3 & 10.2 & 25.3 & 59.2 & 5.5 & 1.21 & $10-20$ & 2.42 \\
\hline E1 & 17.1 & 29.6 & 57.9 & 5.5 & 1.29 & $40-50$ & 2.49 \\
\hline E2 & 20.5 & 42.6 & 68.9 & 6.4 & 1.11 & $30-40$ & 2.46 \\
\hline E3 & 16.0 & 31.7 & 61.0 & 5.8 & 1.02 & $10-20$ & 2.44 \\
\hline F1 & 14.5 & 26.1 & 51.1 & 4.8 & 1.09 & $20-30$ & 2.51 \\
\hline F2 & 7.8 & 21.0 & 46.2 & 4.4 & 0.93 & $0-10$ & 2.47 \\
\hline F3 & 14.0 & 32.2 & 56.8 & 5.6 & 0.85 & $0-10$ & 2.45 \\
\hline
\end{tabular}

"STS: Splitting Tensile Strength; "WA: Water Absorption;

s: Slump; ${ }^{\star A} \mathrm{FD}$ : Fresh Density $\left(\mathrm{gr} / \mathrm{cm}^{3}\right)$ 


\subsection{Fresh concrete behavior}

According to experimental results in Table 5, unit weight of all fresh concretes are higher than conventional concrete (around $2.4 \mathrm{gr} / \mathrm{m}^{3}$ ), and in the heaviest value, the density is higher about $4 \%$ as compared with conventional concrete.

Considering Table 5, the addition of silica nanoparticles in concrete mixture results in intense loss of slump and the loss is dependent on nano-particles content. The reason can be attributed to ultra high specific surface area of nano-particles which is accompanied by absorption of some part of mixing water (Hosseini et al. 2010b; Senff et al. 2009).

Slump loss in one specific mixture in D series $\left(D_{i}\right.$, $\mathrm{i}=1,2,3)$ as compared with the same index in E series $\left(E_{i}\right)$ and slump loss through $E_{i}$ to $F_{i}$, considering the constant contents of silica nano-particles, is related to reduction of water in the first degree, and in the next level is attributed to reduction of cement content and increase in aggregate volume which increases the roughness degree. Obviously, aggregate grading, nominal maximum aggregate size, and overall volume of fine and coarse aggregate (especially coarse aggregate) have significant importance on workability of fresh concrete.

Increasing of coarse aggregate volume in constant volume of concrete contributes to rougher concrete and consequently loss of workability (Waddell, Dobrowolski 2002). On the other side, workability of concrete mixture is dependent on content, fineness, and chemical composition of cement. Generally, in similar conditions, increase in cement content leads to increase in workability (Waddell, Dobrowolski 2002). Slump value has direct relation with water content in mix proportion, and variations in water content (apart from minute changes in contents of other materials) influences the slump values proportionately.

It could be also mentioned other different reasons for slump reduction from witness mixture to D1 such as increase in silica nano-particles and aggregate volume and decrease in water and cement content. Slump increment from D3 to E1 or from E3 to F1 also depends on existence of extra more contents of silica nano-particles (about 3 times) in D3 and E3 respect to that of E1 and F1. This difference could not only cover the influences of water and cement content reduction and increase of aggregate content (factors for slump loss), but also prevail over these factors and finally increase the slump of fresh concrete.

In one specific series (like D) which possess constant cement content, slump reduction is faced as mixture 1 is moved toward mixture 3 . Here, the reason for slump reduction is also regarded to increase in silica nanoparticles in one specific series which could not be affected by increase in water content. Reduction of aggregate content which enhances the slump of concrete is influenced by increase in silica nano-particles. Mixture F3 showed the least value for slump within different mixtures based on highest silica nano-particles content, least cement and water content, and almost highest volume of aggregates.

\subsection{Mechanical behavior}

\subsubsection{Compressive strength}

Figs 2 to 4 depict the compressive strength results for different mix proportions at different ages. According to Fig. 2, in series D, in all different ages of curing, strength has been decreased along with increase in silica nanoparticles. Due to Fig. 3, in series E, from E1 to E2 strength has been developed and from E2 to E3 a descending trend has been observed. In other words, a maximum in strength has occurred in E2. According to Fig. 4, in series $\mathrm{F}$, strength has also reduced from $\mathrm{F} 1$ to $\mathrm{F} 2$ and increased from $\mathrm{F} 2$ to $\mathrm{F} 3$; in fact, the minimum occurred in F2.

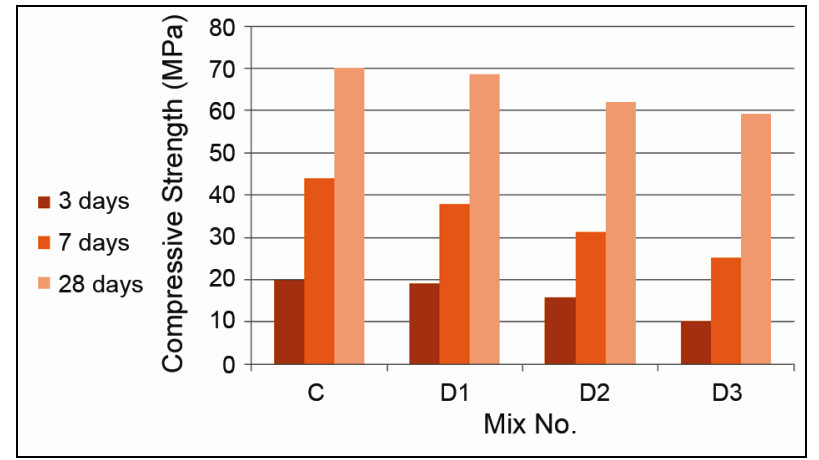

Fig. 2. Comparison of compressive strength in series D with witness mixture $(\mathrm{C})$

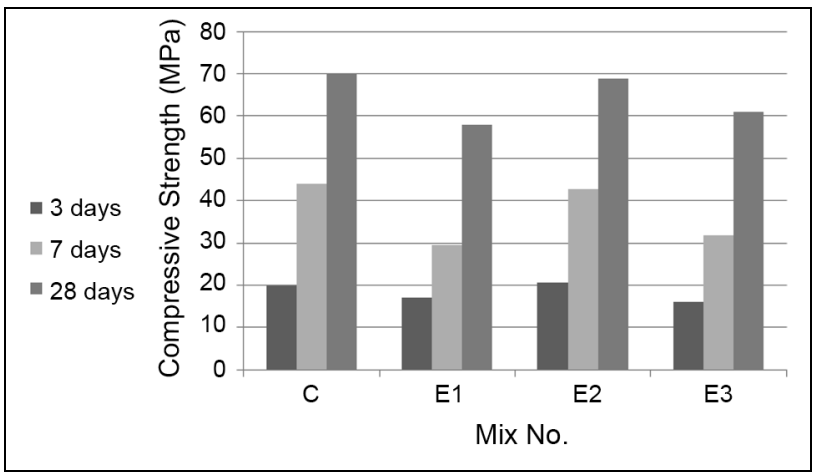

Fig. 3. Comparison of compressive strength in series E with witness mixture $(\mathrm{C})$

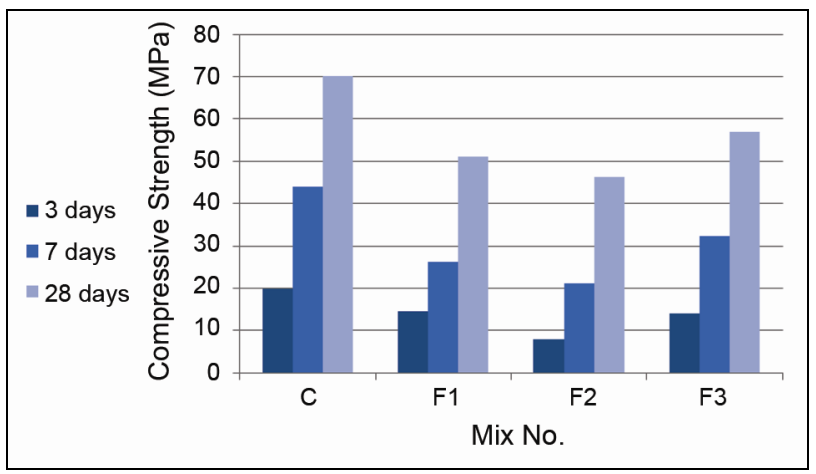

Fig. 4. Comparison of compressive strength in series $\mathrm{F}$ with witness mixture $(\mathrm{C})$ 
28-days compressive strength of D1 is higher than $\mathrm{E} 1$ and $\mathrm{E} 1$ is more than F1. To interpret this fact, it can be mentioned that the cement content has been decreased from D1 to E1 and also from E1 to F1 by holding other design ratios constant. However, aggregate content has also been increased which is negligible comparing with remarkable influence of cement reduction. As it can be noticed, all the mixtures showed lower compressive strengths (28-days) than witness specimens which are directly related to glaring reduction of cement in each series of mix design; since, the target of this study is selected to investigate the feasibility of replacement of cement with silica nano-particles and reduction of cement consumption. According to mixtures, the optimum mechanical mixture is the one with maximum strength within mixtures containing silica nano-particles which actually is mixture possessing closest strength to witness mixture.

$\mathrm{E} 2$ is the maximum and optimum mixture and F2 is the minimum one. Off course, D1 has also close strength to witness mixture; however, it is not the optimum mixture. Because, in E2, 20\% of cement is reduced while in $\mathrm{D} 2,10 \%$ has been replaced. Therefore, considering higher strength and cement reduction of E2, this mix proportion is introduced as the optimum mixture. The reasons for almost equal strength of witness specimen and optimum mixture (made by $20 \%$ replacement of cement with insignificant $2 \%$ silica nano-particles) can be attributed to mechanism which aids the enhancement of micro-structure and consequently mechanical properties (different mechanical factors) and durability of concrete. This mechanism concisely performs in 4 following categories (Hosseini et al. 2010a).

1. Pozzolanic reaction and generating better C-S-H: large amounts of Calcium Hydroxide crystals are produced during the reaction of cement and water (Eqs 1 and 2). Crystals of $\mathrm{Ca}(\mathrm{OH})_{2}$ are hexagonal type and locate in interfacial transition zone between aggregates and cement paste matrix which are harmful for strength and durability of concrete. Silica nano-particles, possessing high specific surface area, can intensely react with $\mathrm{Ca}(\mathrm{OH})_{2}$ and produce C-S-H condensed gel. Hence, during the happenstance of this pozzolanic reaction (eq. 3), amounts and dimensions of crystals of $\mathrm{Ca}(\mathrm{OH})_{2}$ are reduced and C-S$\mathrm{H}$ gel, produced by pozzolanic reaction, forms a denser transition zone and subsequently provides more appropriate strength and durability by filling empty spaces and voids in the matrix:

$$
\begin{aligned}
& 2 \mathrm{C}_{3} \mathrm{~S}+11 \mathrm{H}_{2} \mathrm{O} \rightarrow \mathrm{C}-\mathrm{S}-\mathrm{H}+2 \mathrm{Ca}(\mathrm{OH})_{2} ; \\
& 2 \mathrm{C}_{2} \mathrm{~S}+9 \mathrm{H}_{2} \mathrm{O} \rightarrow \mathrm{C}-\mathrm{S}-\mathrm{H}+\mathrm{Ca}(\mathrm{OH})_{2} ; \\
& 2 \mathrm{SiO}_{2}+3 \mathrm{Ca}(\mathrm{OH})_{2} \rightarrow 3 \mathrm{CaO} \cdot 2 \mathrm{SiO}_{2} \cdot \mathrm{H}_{2} \mathrm{O} .
\end{aligned}
$$

To describe the ultra rapid reactions of silica nanoparticles, it can be said that silica nano-particles, possessing numerous unsaturated binds located at their surfaces, would initiate a reaction between $\mathrm{SiO}_{2}$ and $\mathrm{Ca}(\mathrm{OH})_{2}$ and consequently fast chemical reactions among (三Si-O-) and (三Si-) and water molecules (Qing et al. 2007).
2. Micro and Nano-filling effect: nano-particles can fill a notable part of voids existing in the matrix of cement paste even in agglomerated manner, regarding their ultra fine dimension. On other side, about $70 \%$ of hydration productions are C-S-H gel. Average diameter of particles of C-S-H gel is around $10 \mathrm{~nm}$ (Ye 2001). Nano-particles accompanied by filling ability of produced C-S-H can form a far condensed cement paste. Thus the porosity decreases and the strength of ITZ increases. Because Van der waals force between cement paste and aggregates is closely related to the degree of density of ITZ (Li et al. 2006a).

3. Acting as a nucleus: when a small amount of nano-particles are uniformly dispersed in the cement paste, the nano-particles act as a nucleus to tightly bond with cement hydrate and also to promote hydration of cement due to their high activity, which is favorable for the strength of cement mortar. The hydrate products of cement will deposit on the nano-particles during hydration due to their great surface energy and will grow to form conglomeration containing the nano-particles as nucleus (Li et al. 2004b).

4. Controlled crystallization: if the content of nanoparticles and the distance between them are appropriate, the crystallization will be controlled to produce a suitable state by restricting the growth of $\mathrm{Ca}(\mathrm{OH})_{2}$ and AFm crystals. This makes the cement matrix more homogeneous and compact (densification effect) (Li et al. 2004b).

Now this question is propounded that what was the reason for maximizing the strength in E2 within different other mixtures containing silica nano-particles, and why other mixtures reached lower strength, or why in series D the strength decreased while the dosage of nano-particles was increasing. This issue can be originated from continues of pozzolanic reaction due to existence of plenty of silica nano-particles. Besides, silica nano-particle is almost a kind of inadhesive material, and by adding the feature of owning ultra high specific area and high surface energy of these particles, physical reaction would happen between nano-particles which will result in attraction of each other (Li et al. 2004a, b). The more the number of silica nano-particles the higher the capability of these particles to gather around each other in the concrete matrix. This fact can contribute to conglomeration of nano-particles in concrete matrix (without happenstance of any chemical reaction) and subsequently strength loss; because the newly formed conglomerations are weak and alterable.

Another point to mention in this study is different type of performance of silica nano-particles in concrete matrix, such as reduction of strength by increase in nanoparticles dosage in mixtures of series D and concurrently reduction in water absorption (enhancement) or E2 and D1 which gained the highest strength in mixtures with silica nano-particles. This different behavior of silica nano-particles can be discerned by considering both cement reduction and aggregate increment. Because cement reduction on one side causes the strength loss and on other side results in free $\mathrm{Ca}(\mathrm{OH})_{2}$ produced by hydration reaction which decreases the pozzolanic influence of silica nano-particles. 
Moreover, this cement reduction is accompanied by increase in aggregate volume in concrete matrix and larger voids are formed in matrix which enfeebles the micro-filling effect of silica nano-particles and on other side the conglomeration is also probable. Because larger voids require higher content of nano-particles; so, the existing nano-particles may be insufficient to fill these voids and even if they become sufficient, by congregation of nanoparticles in big voids, large number of these particles would gather together and inevitably conglomeration will occur. On the other side, the reduction of workability of concrete is a supportive factor in the formation of microcracks which have negative effect on the compressive strength (Li et al. 2006b).

By summing up the discussed issues and mentioning that the interaction between discussed factors resulted in such complicated behavior in fabricated specimens, we can interpret the optimization of strength in D1 and E2.

\subsubsection{Splitting tensile strength}

Results for Brazilian tensile strength are shown in Table 5. Regarding weak tensile strength of concrete, usually it is not expected from concrete to oppose direct tensile forces. But tensile strength against cracks formed by shrinkages made by chemical reaction, drying or temperature shocks is significantly important (Waddell, Dobrowolski 2002). Direct tensile strength test is rarely conducted due to unavoidable secondary stresses applied by sustaining gages. Hence, the most common method in measuring the tensile strength of concrete is splitting tensile strength (ASTM C496/C496M-11 2011) which is the same as Brazilian tensile strength (Mehta, Monteiro 2006).

According to Fig. 5, which depicts a kind of comparing outline for 28-days Brazilian tensile strength among different series, almost similar behavior for 28-days compressive strength can be observed. Considering the fact that all of strengths of concrete are to somehow related to 28-days compressive strength of concrete (Waddell, Dobrowolski 2002), mentioned interpretations for compressive strength in previous section (3.2.1) are also applicable here. The same as compressive strength, E2 is the optimum mixture and F2 performed poorer (minimum) comparing other mix proportions.

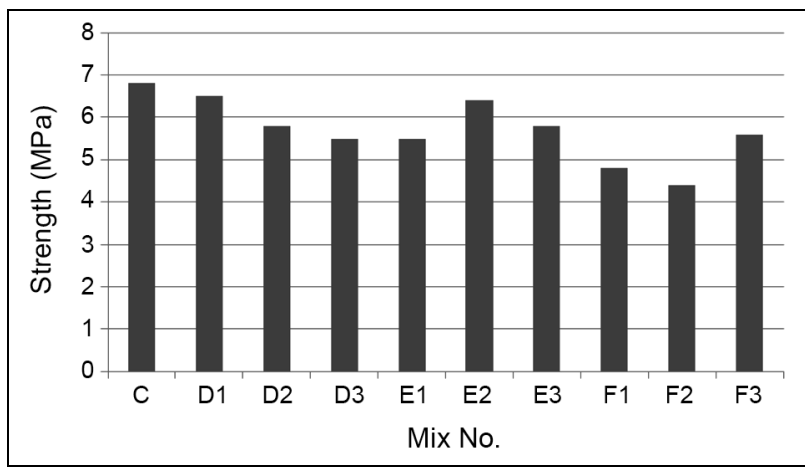

Fig. 5. Comparison for splitting tensile strength of all mixtures at 28-days

\subsection{Water absorption}

The water absorption test is one of the most important tests in measuring concrete durability. The total amount of water absorption is an indicator for concrete durability. Water absorption is a process in which water enters into the concrete voids and saturates the matrix pores. As it can be seen in Table 5, which indicates the results of water absorption test (ASTM C642-97 1997), in one series (eg. D) the amount of water absorption is decreased with an increase in the amount of silica nano-particles. Comparing different series, the water absorption is lowered as the amount of cement is decreased.

Regarding this fact that the cement paste is the most permeable part of concrete, the water absorption will increase with increase in volume of paste in a constant amount of concrete. On the other hand, increasing of aggregate volume as a permeable constituent with low amount of water absorption can be effective on concrete water absorption (Waddell, Dobrowolski 2002). The better performance of transmission zone is also one of the most significant reasons in better permeability of concrete. This issue is very important especially in using nano-particles and micro-particles of silica. Hence, the results indicate that in one series (eg. D), aggregate volume will decrease as dosage of nano-silica increases, and cement paste volume decreases while water content has increased.

The decrease in aggregate volume and increase in cement paste volume which include tiny changes, are factors helping increase of water absorption. While nanosilica, regarding its mechanism in concrete microstructure which leads to more dense concrete by filling the existing voids, has a remarkable effect in decreasing the water absorption like a super pozzolan. So, it can negate the effect of little amount of volume reduction of aggregates and increase of cement paste (water absorption increasing factors), and finally decreases the water absorption.

The decrease in water absorption in mixtures containing silica nano-particles comparing to the witness mixture is also related to the decrease in volume of cement paste. The interesting point in water absorption test is increase of water absorption in first mixture of a specific series (eg. E1) comparing the third mixture of the last series (eg. D3). For instance, comparing E1 and D3, it is clear that although the volume of cement has been decreased, usage of more contents of silica nano-particles (3\%) have been able to dense the cement paste matrix in a way that remarkable permeability reduction has been observed. So, the pozzolanic performance of silica nanoparticles is vividly clear in the case of concrete durability.

\subsection{Microstructure}

According to the Figs 6 to 13 which indicate the results of the SEM and EDAX tests, the performance of nanoparticles in the interfacial transition zone between paste and aggregate can be locally examined. These figures show the results of the examination of concrete matrix microstructure from mixtures C, D1, D2, and D3. As it can be seen, as the amount of silica nano-particles increases, the concrete matrix becomes denser in the inter- 
facial transition zone between paste and aggregate which can be a result of severe pozzolanic characteristic of silica nanostructures and formation of the dense gel of Calcuim-Silicate-Hydrate on one side, and high micro-filling characteristic of these particles (the mechanism of this characteristic has mentioned in parts 1,2 and 3) on the other side. However, the most notable issue in this research is different performance of nano-particles in concrete matrix. The strength has been reduced in some cases though the structure is denser and the permeability characteristics are better, which can be a result of reduction of cement. This reduction leads to some changes in the four main behaviors of nano-particles.

The comparison between the SEM pictures shown in Figs 6 to 9, indicate that the increase in the amount of nano-particles leads to a denser structure of paste in the interfacial transition zone between paste and aggregate, but this cannot be the only reason for strength loss, because strength is the result of the holistic structure of concrete matrix. As it is mentioned in the parts 1,2 and 3, a specific reason cannot be mentioned for this difference by only examination of microstructure in the interfacial transition zone. However, the examination of microstructure can be a trustable test for investigating the reduction in permeability, because cement paste is the most influential factor on concrete permeability while aggregates possess lowest water absorption, based on what has been discussed in previous section.

Therefore, the formation of dense structure in the cement paste and also in interfacial transition zone can decrease the permeability of concrete. Furthermore, the enhancement of matrix of transition zone can be analyzed differently using the EDAX test results which have been shown in Figs 10 to 13. These figures indicate that using nano-particles leads to increase in the amount of $\mathrm{Ca}$ and $\mathrm{Si}$. On the other hand, increasing the amount of nanoparticles increases the amount of $\mathrm{Ca}$ and $\mathrm{Si}$ in the ITZ which is a sign of higher volumes of produced C-S-H gel. Also, it is clear that the amount of Si in D3 is a lot more than the other mixtures. This is an indication of aggregation of silica nano-particles in some places which can lead to conglomeration in some cases and exertion of negative effects on the strength of ITZ matrix.

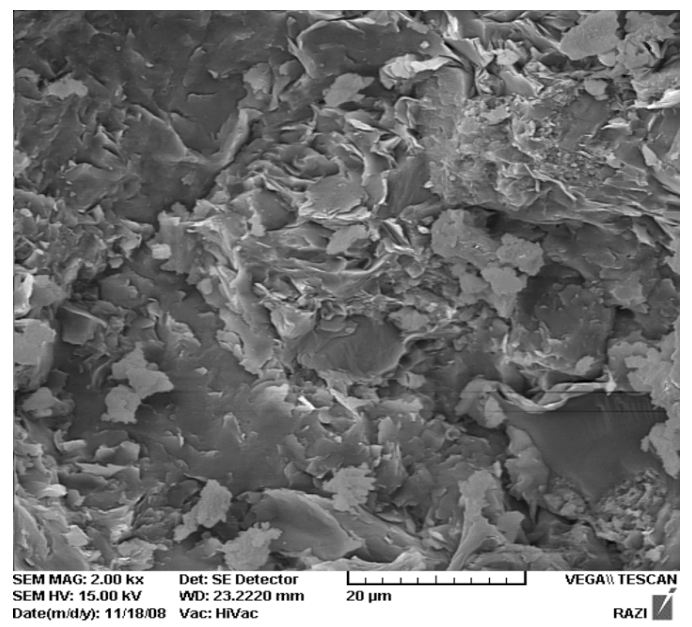

Fig. 6. ITZ of Mixture C

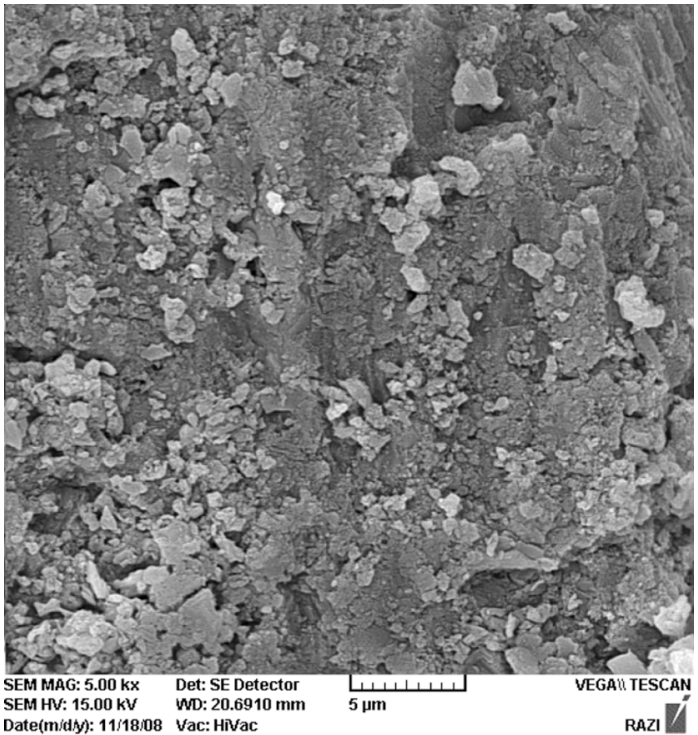

Fig. 7. ITZ of Mixture D1

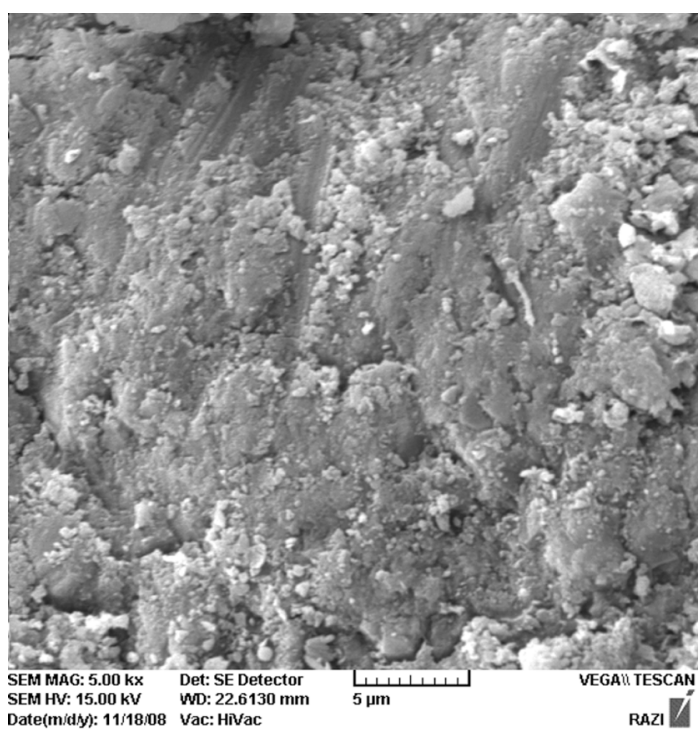

Fig. 8. ITZ of Mixture D2

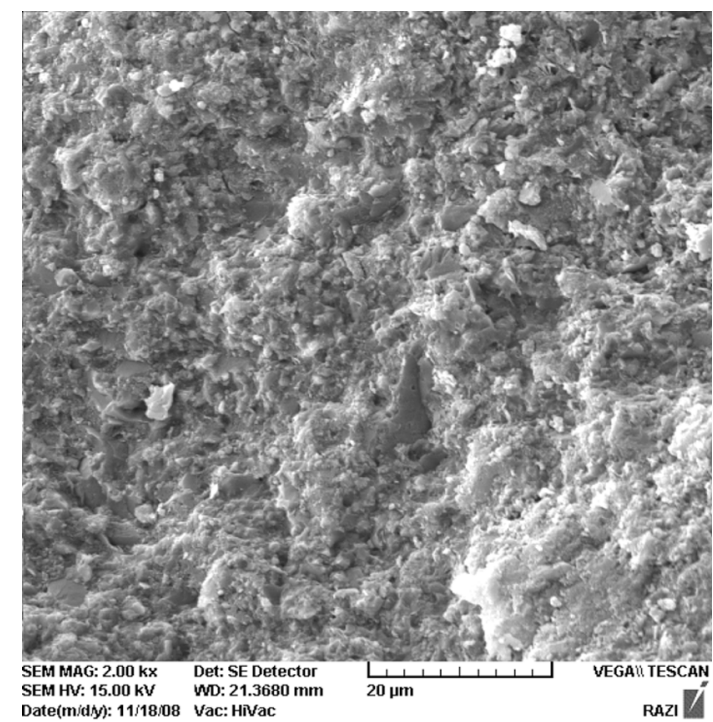

Fig. 9. ITZ of Mixture D3 


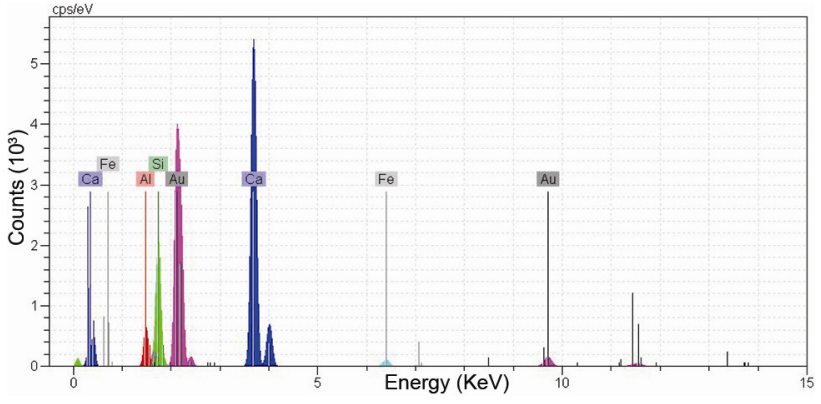

Fig. 10. EDX spectrum on the surface of aggregate (Mix No. C)

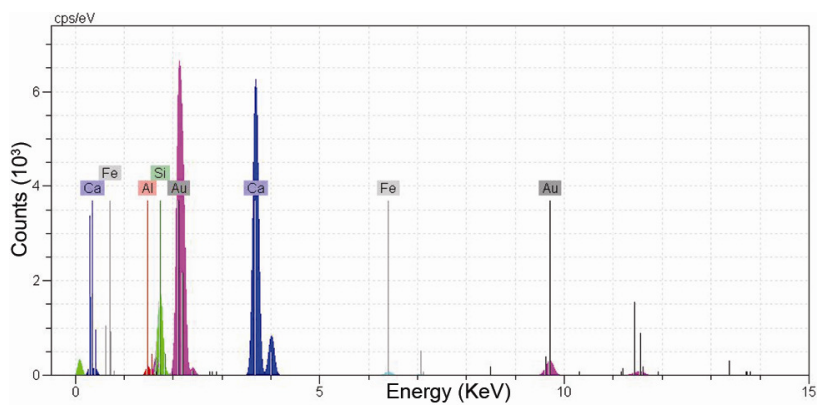

Fig. 11. EDX spectrum on the surface of aggregate (Mix No. D1)

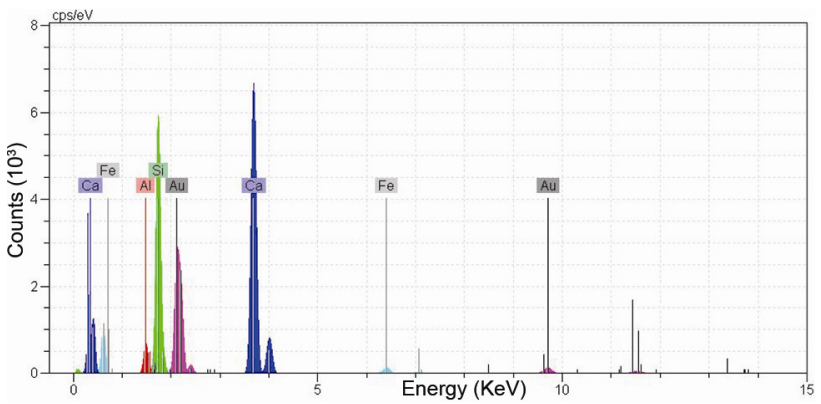

Fig. 12. EDX spectrum on the surface of aggregate (Mix No. D2)

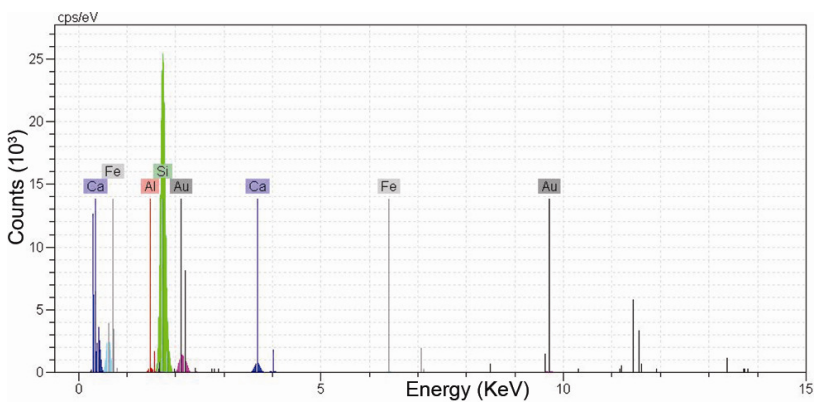

Fig. 13. EDX spectrum on the surface of aggregate (Mix No. D3)

\section{Conclusions}

Based on this research and its experimental results the following points can be mentioned:

- Regarding the superior pozzolanic performance of silica nano-particles, it will be very fruitful to use them in concretes. But, the most notable issue is using low amount of nano-particles for achieving the best performance in matrix of cement based materials, and also preventing extra costs in one cubic meter concrete. Using low amount of nano-particles can lead to a better dispersion of these particles in concrete mixture and improve their performance.

- Based on the experimental data, application of silica nano-particles has been beneficial in reduction of cement consumption. As it became clear, the mixtures E2 and D1 approached to the strength of the main mixture. Considering 20\% reduction of cement in E2 and 10\% in D1, and minute difference of silica nano-particles between these two mixtures, mixture E2 has been selected as the optimum one.

- Based on the slump test results, there has been a severe slump loss with increase in the amount of silica nano-particles, while the ratio of superplasticizers to cementitious materials has been held constant to omit the effect of superplasticizers on the slump of fresh concretes. This phenomenon is a result of high specific surface area of nano-particles which can absorb some of the water content with their high absorption by surface.

- The results of this research also emphasize the relation between tensile and compressive strength. Because the changing trend in 28-days tensile strength is similar to that of compressive strength at the same age. Hence, the mixtures E2 (20\% reduction in cement, $2 \%$ increase of silica) and D1 ( $10 \%$ reduction of cement, $1 \%$ increase in silica) have had the closest Brazilian tensile strength to the witness mixture, and as it has been mentioned before, the E2 mixture is still the optimum one.

- Due to reduction of water absorption in concrete specimens containing higher amounts of silica nano-particles, it can be deduced that silica nanoparticles are very effective in decreasing the permeability of concrete. This can be a result of mechanism of performance of silica nanoparticles in concrete matrix which reacts with $\mathrm{Ca}(\mathrm{OH})_{2}$ and produces $\mathrm{C}-\mathrm{S}-\mathrm{H}$ gel which makes the micro-structure of concrete denser, and as a micro and nano-filler fills the small voids inside concrete.

- Regarding the micro-structural tests in the interfacial transition zone, addition of silica nanoparticles makes this zone denser due to their four main behaviors, and compacts and improves overall properties of this zone.

\section{Acknowledgement}

This paper is derived from the project named DAM485004 sponsored by Power Ministry of Iran and Iran Water Resource Management Co. Therefore, the authors of this paper appreciate Power Ministry and Iran Water Resource Management Co. for their financial supports. 


\section{References}

ASTM C127-01 Standard Test Method for Density, Relative Density (Specific Gravity), and Absorption of Coarse Aggregate. American Society for Testing and Materials (ASTM), 2001. $6 \mathrm{p}$.

ASTM C128-01 Standard Test Method for Density, Relative Density (Specific Gravity), and Absorption of Fine Aggregate. American Society for Testing and Materials (ASTM), 2001.6 p.

ASTM C138-01 Standard Test Method for Unit Weight, Yield, and Air Content (Gravimetric) of Concrete. American Society for Testing and Materials (ASTM), 2001. 3 p.

ASTM C143/C143M-03 Standard Test Method for Slump of Hydraulic Cement Concrete. American Society for Testing and Materials (ASTM), 2003. 4 p.

ASTM C496/C496M-11 Standard Test Method for Splitting Tensile Strength of Cylindrical Concrete Specimens. American Society for Testing and Materials (ASTM), $2011.5 \mathrm{p}$.

ASTM C496-96 Standard Test Method for Splitting Tensile Strength of Cylindrical Concrete Specimens. American Society for Testing and Materials (ASTM), 1996. 4 p.

ASTM C642-97 Standard Test Method for Density, Absorption, and Voids in Hardened Concrete. American Society for Testing and Materials (ASTM), 1997. 3 p.

ASTM C642-97 Standard Test Method for Density, Absorption, and Voids in Hardened Concrete. American Society for Testing and Materials (ASTM), 1997. 3 p.

Bahadori, B.; Hosseini, P.; Eslami, E. 2009. The role of nanoparticles in sustainable development of concrete industry, Journal of Concrete Research 2(3): 31-43 (in Persian).

BS 1881-113:2011 Testing concrete. Method for making and curing no-fines test cubes. British Standards Institution, 2011. $11 \mathrm{p}$.

Chung, D. D. L. 2002. Review: improving cement-based materials by using silica fume, Journal of Materials Science 37(4): 673-682. http://dx.doi.org/10.1023/A:1013889725971

Collepardi, S.; Borsoi, A.; Ogoumah Olagot, J. J.; Troli, R.; Collepardi, M.; Cursio, A. Q. 2005. Influence of nanosized mineral additions on performance of SCC, in Proc. of the $6^{\text {th }}$ International Congress "Global Construction, Ultimate Concrete Opportunities”, 5-7 July, 2005, Dundee, UK.

Damtoft, J. S.; Lukasik, J.; Herfort, D.; Sorrentino, D.; Gartner, E. M. 2008. Sustainable development and climate change initiatives, Cement and Concrete Research 38(2): 115127. http://dx.doi.org/10.1016/j.cemconres.2007.09.008

Hale, M. W.; Seamus, F. F.; Bush, Jr., T. D.; Russell, B. W. 2008. Properties of concrete mixtures containing slag cement and fly ash for use in transportation structures, Construction and Building Materials 22(9): 1990-2000. http://dx.doi.org/10.1016/j.conbuildmat.2007.07.004

Hosseini, P.; Booshehrian, A.; Farshchi, S. 2010a. Influence of nano- $\mathrm{SiO}_{2}$ addition on microstructure and mechanical properties of cement mortars for ferrocement, Transportation Research Record: Journal of Transportation Research Board 2141: 15-20. http://dx.doi.org/10.3141/2141-04

Hosseini, P.; Nekooie, M. A.; Rafiei, S.; Madari, A. 2010 b. Investigation on the performance of self consolidating mortars by utilization of silica nano particles, in Proc. of the $3^{\text {rd }}$ International Graduate Conference on Enginee- ring, Science and Humanity 2010 (IGCESH 2010), 2-4 November, 2010, Johor Bahru, Malaysia.

Ji, T. 2005. Preliminary study on the water permeability and microstructure of concrete incorporating nano- $\mathrm{SiO}_{2}, \mathrm{Ce}$ ment and Concrete Research 35(10): 1943-1947. http://dx.doi.org/10.1016/j.cemconres.2005.07.004

Jo, B.-W.; Kim, C.-H.; Tae, G.-h.; Park, J.-B. 2007. Characteristics of cement mortar with nano- $\mathrm{SiO}_{2}$ particles, Construction and Building Materials 21(6): 1351-1355. http://dx.doi.org/10.1016/j.conbuildmat.2005.12.020

Khaloo, A. R.; Hosseini, P. 2008. Investigation on relationship between compressive strength and micro-structure of cement mortar containing various pozzolans and nano particles, Journal of Iranian Concrete Institute 30: 17-22. (in Persian).

Khaloo, A. R.; Hosseini, P. 2009. Domestication of special concretes, an important way to sustainable development of concrete industry (part2: Sustainable development is a result of domestication), Journal of Iranian Concrete Institute 33: 17-24. (in Persian).

Li, G.; Zhao, X. 2003. Properties of concrete incorporating fly ash and ground granulated blast-furnace slag, Cement and Concrete Composites 25(3): 293-299.

http://dx.doi.org/10.1016/S0958-9465(02)00058-6

Li, H.; Xiao, H.-g.; Ou, J.-p. 2004a. A study on mechanical and pressure-sensitive properties of cement mortar with nanophase materials, Cement and Concrete Research 34(3): 435-438. http://dx.doi.org/10.1016/j.cemconres.2003.08.025

Li, H.; Xiao, H.-g.; Yuan, J.; Ou, J. 2004b. Microstructure of cement mortar with nano-particles, Composites Part B: Engineering 35(2): 185-189. http://dx.doi.org/10.1016/S1359-8368(03)00052-0

Li, Z.; Wang, H.; He, S.; Lu, Y.; Wang, M. 2006a. Investigation on the preparation and mechanical properties of the nanoalumina reinforced cement composite, Materials Letters 60(3): 356-359. http://dx.doi.org/10.1016/j.matlet.2005.08.061

Li, H.; Zhang, M.-h.; Ou, J.-p. 2006b. Abrasion resistance of concrete containing nano-particles for pavement, Wear 260(11-12): 1262-1266. http://dx.doi.org/10.1016/j.wear.2005.08.006

Mehta, P. K.; Monteiro, P. J. M. 2006. Microstructure, Properties, and Materials. $3^{\text {rd }}$ Ed. McGraw-Hill. $659 \mathrm{p}$.

Naji Givi, A.; Abdul Rashid, S.; Aziz, F. N. A.; Mohd Salleh, M. A. 2010. Experimental investigation of the size effects of $\mathrm{SiO}_{2}$ nano-particles on the mechanical properties of binary blended concrete, Composites Part B: Engineering 41(8): 673-677. http://dx.doi.org/10.1016/j.compositesb.2010.08.003

Ortiz, O.; Castells, F.; Sonnemann, G. 2009. Sustainability in the construction industry: a review of recent developments based on LCA, Construction and Building Materials 23(1): 28-39.

http://dx.doi.org/10.1016/j.conbuildmat.2007.11.012

Penpolcharoen, M. 2005. Utilization of secondary lead slag as construction material, Cement and Concrete Research 35(6): 1050-1055.

http://dx.doi.org/10.1016/j.cemconres.2004.11.001

Qing, Y.; Zenan, Z.; Deyu, K.; Rongshen, C. 2007. Influence of nano- $\mathrm{SiO}_{2}$ addition on properties of hardened cement paste as compared with silica fume, Construction and Building Materials 21(3): 539-545.

http://dx.doi.org/10.1016/j.conbuildmat.2005.09.001 
Ramezanianpour, A. A.; Mahdi khani, M.; Ahmadibeni, G. 2009. The effect of rice husk ash on mechanical properties and durability of sustainable concrete, International Journal of Civil Engineering 7(2): 83-91.

Roy, D. M.; Arjunan, P.; Silsbee, M. R. 2001. Effect of silica fume, metakaolin, and low-calcium fly ash on chemical resistance of concrete, Cement and Concrete Research 31(12): 1809-1813.

http://dx.doi.org/10.1016/S0008-8846(01)00548-8

Senff, L.; Labrincha, J. A.; Ferreira, V. M.; Hotza, D.; Repette, W. L. 2009. Effect of nano-silica on rheology and fresh properties of cement pastes and mortars, Construction and Building Materials 23(7): 2487-2491.

http://dx.doi.org/10.1016/j.conbuildmat.2009.02.005
Senff, L.; Hotza, D.; Repette, W. L.; Ferreira, V. M.; Labrincha, J. A. 2010. Mortars with nano- $\mathrm{SiO}_{2}$ and micro- $\mathrm{SiO}_{2}$ investigated by experimental design, Construction and Building Materials 24(8): 1432-1437.

http://dx.doi.org/10.1016/j.conbuildmat.2010.01.012

Waddell, J. J.; Dobrowolski, J. A. 2002. Concrete Construction Handbook. $3^{\text {rd }}$ Ed. Mcgraw-Hill. 1024 p.

Ye, Q. 2001. Study and development of nano-composite cement-based material, Gypsum and Cement for Building 11: 4-6.

Zhang, M.-h.; Li, H. 2011. Pore structure and chloride permeability of concrete containing nano-particles for pavement, Construction and Building Materials 25(2): 608-616. http://dx.doi.org/10.1016/j.conbuildmat.2010.07.032

Hadi BAHADORI. Dr, assistant professor of civil engineering. He is a member of the scientific advisory board of Urmia University. His major interest is the experimental researches on concrete and geomaterials. He is a member of the international society of soil mechanics and geotechnical engineering (ISSMGE). He is the manager of 2 national projects about nano-particles application in green concrete.

Payam HOSSEINI. Eng., researcher in Concrete \& Advanced Materials Group (CAMG) of Tolou Technology Development Institute at the Sharif University of Technology. He is a member of ACI Committe 236-D, Material ScienceNanotechnology of Concrete, and ACI Committee 236-TG2, Sustainability Engineered by Material Science. His research interests include the nano-engineered cementitious composites, green management in concrete industry and sustainable cement-based materials. 